\title{
STRUCTURAL CHARACTERISTICS OF SNOW DRIFTS AND CORNICES
}

\author{
by
}

Renji Naruse, Hiroshi Nishimura and Norikazu Maeno

Institute of Low Temperature Science, Hokkaido University, Sapporo, Japan 060

\begin{abstract}
Sorting effects of snow particles during deposition were studied in field observations of snow cornices and wind-tunnel experiment of snow drifts. Grain size, density and hardness were larger at the upper part (root) of a cornice than at the lower part (scarp). Experiments with the use of a horizontal step in a wind-tunnel revealed the importance of redistribution of snow particles on the formation of drifts: at wind speed of $5 \mathrm{~m} / \mathrm{s}$, about $40 \%$ of particles fallen onto the surface behind a $0.1-\mathrm{m}$ high step were removed by erosion, rebound and creep. The surface mass balance controlling the growth and shape of a drift are briefly discussed.
\end{abstract}

\section{INTRODUCTION}

A snow cornice is a type of snow drift, usually formed in irregular terrain by the deposition of blowing snow particles. Among a number of researches on cornices in mountain regions, and drifts around houses, roads and fences, some gave qualitative characteristics of formation and structure (eg Seligman 1962) and empirical methods for planning against them (eg Tabler 1980). The present paper gives results of field observations and wind-tunnel experiments which were carried out to clarify the growth mechanism and physical properties of cornices and drifts.

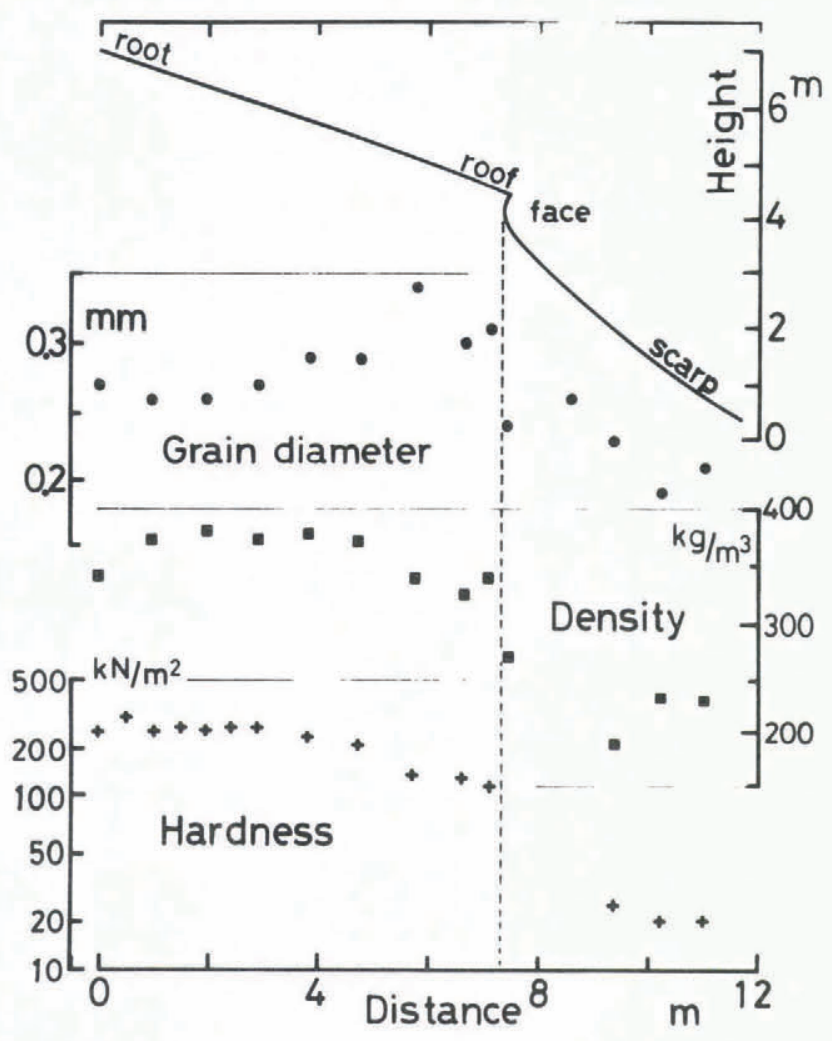

Fig.1. The surface profile, and mean grain diameter, bulk density and hardness of surface snow of a cornice in $\mathrm{Mt}$ Daisetsu, 27 February 1979.
PHYSICAL PROPERTIES OF SNOW IN CORNICES

Measurements were made of shape, layer structures and various other properties including plastic deformation of snow cornices at Mt Asahidake, Hokkaido, Japan (Naruse and Nishimura 1979; Naruse 1980). Figure 1 shows an example of the results. Mean grain diameter, bulk density and hardness of the surface layer $(0.05-0.15 \mathrm{~m}$ deep) are larger at the root and roof than at the scarp. This results from sorting of snow particles in the deposition-erosion process: smaller particles tend to be lifted up with ease from the surface by wind or collisions of falling particles, so that most of the smaller ones are transported over the face and deposited on the scarp, while the larger ones are left on the root and roof. Lower values of density and hardness were observed at the scarp; the most likely cause is a less effective compaction of snow on the leeward surface due to weaker wind and smaller falling velocities of small snow particles.

\section{STRUCTURE AND GROWTH OF MODEL DRIFTS}

Steps of 0.05 and $0.1 \mathrm{~m}$ high were set up as simple models of undulating terrain at the leeward end of a cold wind-tunnel, in which blowing snow was formed continuously (Maeno and others 1984). A slat-and-box snow collector was placed parallel behind the step, as shown in Figure 2. A snow drift was formed on the slat and all the falling particles were trapped by the collector which had 10

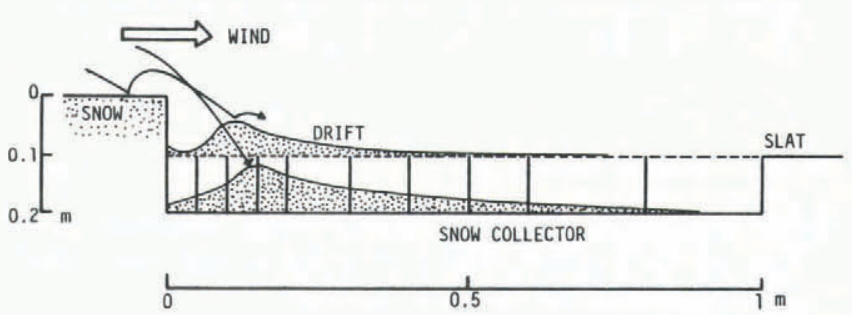

Fig.2. Apparatus for the wind-tunnel experiment. The upper face of the snow collector is placed at the same level with and in parallel with a slat.

boxes. Each experiment was run for 10 minutes at -10 or $-15^{\circ} \mathrm{C}$, and at wind speeds of 5 or $8 \mathrm{~m} / \mathrm{s}$.

Snow particles were collected with an oil-coated glass plate laid horizontally behind the step. The number of particles obtained as functions of the distance from the step and particle size are illustrated in Figure 3. Most particles larger than $0.47 \mathrm{~mm}$ fall around $0.1 \mathrm{~m}$ from the step where the crest of the drift is formed. Smaller particles are observed in the far leeward region. The result indicates sorting of particles over the step: larger particles tend to fall down in the vicinity of the step but smaller ones can be transported further by the air flow.

Figure 4 shows water-equivalent height of fallen snow (P) trapped with the collector and that of a drift formed on the slat $(\mathrm{Hw})$ measured by a snow sampler $19 \mathrm{~mm}$ in diameter, plotted against distance $\mathrm{x}$ from the step. The data are averages of three experiments at $5.2 \mathrm{~m} / \mathrm{s}$. The crest of the drift is located between the step and the maximum position of $\mathrm{P}$, and that the total amount of $\mathrm{Hw}$ is smaller 

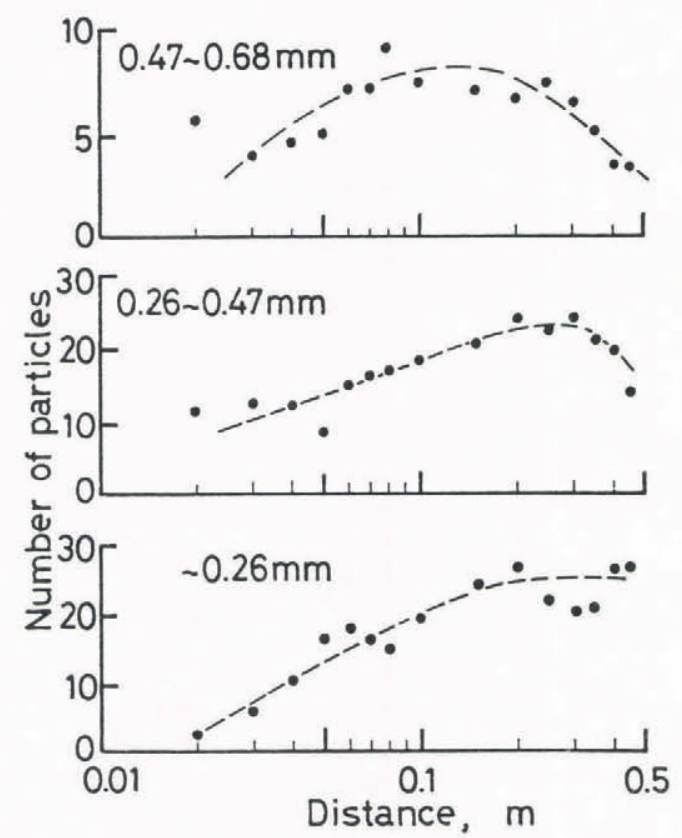

Fig.3. Distribution of grain diameters on the leeward surface of a $0.05 \mathrm{~m}$ high step; wind speed: $5 \mathrm{~m} / \mathrm{s}$.

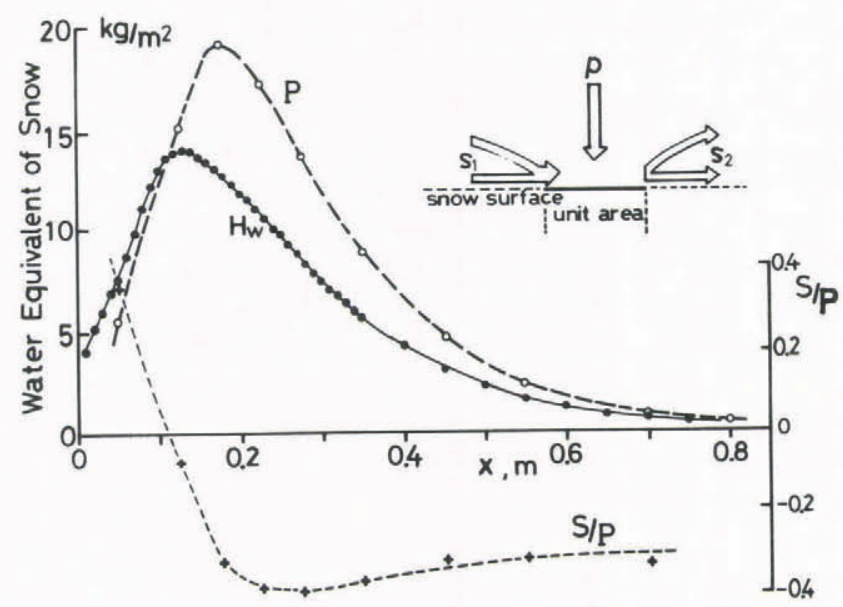

Fig.4. Distributions of fallen snow $P$ and deposited snow $\mathrm{Hw}$ on the leeward surface of a $0.1 \mathrm{~m}$ high step; wind speed: $5.2 \mathrm{~m} / \mathrm{s}$. S/P is given by $\mathrm{Hw} / \mathrm{P}-1$.

than that of $P$. The results show again that redistribution of fallen snow should have occurred on the drift surface.

\section{MASS BALANCE ON THE DRIFT SURFACE}

We consider the mass balance in a unit area on the drift surface. Let $p$ be the mass flux of falling particles directly over the step, and $s_{1}$ and $s_{2}$ be the incoming and outgoing mass fluxes due to redistribution by creeping, rebounding and other erosion processes. $\mathrm{p}$ is only a function of $x$, while $s_{1}$ and $s_{2}$ are functions of $x$ and time $t$ since the surface slope and height changed gradually. Then the continuity equation is given by

$$
\partial H w / \partial t=p+s_{1}-s_{2} .
$$

Integrating Equation 1 from $t=0$ to $t=t$,

$$
H w=\int_{0}^{t} p d t+\int_{0}^{t}\left(s_{1}-s_{2}\right) d t=P+S
$$

is obtained.

The observed ratio $S / P$ is shown in Figure 4. The positive ratio represents the gain of mass, and the negative the loss due to redistribution. It is noted that the region near the step shows positive $\mathrm{S} / \mathrm{P}$ and that in the leeward of the crest of drift negative. Furthermore the minimum of $\mathrm{S} / \mathrm{P}$ is located near an inflexion point of the profile of $\mathrm{Hw}$. It is suggested that $\mathrm{S} / \mathrm{P}$ depends also on the wind speed, structure of turbulence, step height, and various properties of snow particles. Negative values of $\mathrm{S} / \mathrm{P}$ as large as -1 were obtained on the leeward part of the drift in a strong wind of $8 \mathrm{~m} / \mathrm{s}$, and $S / P$ was nearly zero for fresh snow particles. More detailed studies are under way to get a deeper insight into the formation mechanism of drifts.

\section{ACKNOWLEDGEMENTS}

Thanks are due to $\operatorname{Dr} \mathrm{S}$ Kobayashi, and Messrs I Takei and T Ebinuma of ILTS of Hokkaido University for their help and discussions.

\section{REFERENCES}

Maeno N, Kobayashi S, Naruse R, Nishimura H, Takei I, Ebinuma T, Kaneda Y, Ishida T 1984 Wind-tunnel experiments of blowing snow. Annals of Glaciology 6: 63-67

Naruse R 1980 The surface shape of snow cornices. Low Temperature Science A(39): $75-80$

Naruse R, Nishimura H 1979 Structures and properties of snow cornices I. Low Temperature Science A(38): 41-51

Seligman G 1962 Snowstructure and ski field. Edinburgh, $\mathrm{R}$ \& $\mathrm{R}$ Clark

Tabler R D 1980 Geometry and density of drift formed by snow fences. Journal of Glaciology 26(94): 405-419 